\title{
Desempenho fisiológico de sementes de algodão cultivadas em Luís Eduardo Magalhães, Bahia
}

\section{Physiological performance of cottonseed grown in Luís Eduardo Magalhães, Bahia}

\author{
Renan Thiago Carneiro Nunes ${ }^{1 *}$, Thiago Reis Prado ${ }^{1}$, Edenilson Batista Ribeiro ${ }^{1}$, Willian Santos do Vale ${ }^{2}$, Otoniel Magalhães \\ Morais $^{3}$
}

\begin{abstract}
RESUMO: O presente trabalho foi desenvolvido no laboratório de tecnologia de sementes da Universidade Estadual do Sudoeste da Bahia, Campus de Vitória da Conquista UESB, com objetivo de avaliar a qualidade fisiológica de sementes de algodão (Gossypium hirsutum L.), utilizando-se cinco cultivares (DP 604, FM 993, BRS 368, TMG 642 e DELTA OPAL). As sementes foram submetidas aos seguintes testes: teor de água, peso de mil sementes, germinação, primeira contagem de germinação, índice de velocidade de emergência, emergência, comprimento da parte aérea, massa seca das plântulas e condutividade elétrica. O delineamento experimental utilizado foi o inteiramente casualizado, em quatro repetições de 50 sementes por tratamento. A cultivar TMG 642 demonstrou baixa qualidade fisiológica das sementes, quando comparados com as cultivares DP 604, FM 993, BRS 368, e DELTA OPAL. Os testes de germinação, condutividade elétrica e índice de velocidade de germinação mostraram eficiência na separação de cultivares de sementes de algodão em níveis de vigor.
\end{abstract}

Palavras-chaves: Gossypium hirsutum L, Cultivares, Vigor.

ABSTRACT: This study was conducted at the State University of seed technology laboratory of Southwest Bahia, Campus Victory Conquest, UESB, to evaluate the physiological quality of cotton seeds (Gossypium hirsutum L.), using five cultivars (DP 604, FM 993, BRS 368, GMT 642 and DELTA OPAL). Seeds were subjected to the following tests: water content, weight of a thousand seeds, germination, first count, emergence speed index, emergency, shoot length, dry mass of seedlings and electrical conductivity. The experimental design was completely randomized, with four replications of 50 seeds per treatment. The cultivar TMG 642 demonstrated low physiological seed quality when compared with the DP 604 cultivars, FM 993, BRS 368, and DELTA OPAL. Germination tests, electrical conductivity and germination rate index showed efficiency in the separation of cotton seed varieties in force levels.

Key words: Gossypium hirsutum L, cultivars, Vigor.

\footnotetext{
*Autor para correspondência

Recebido para publicação em 07/08/2015; aprovado em 20/11/2015

${ }^{1}$ Engenheiro Agrônomo (UESB), Mestrando em Agronomia (UESB), Vitória da Conquista, Bahia. E-mail: renanthiago_tn@hotmail.com;

${ }^{2}$ I Engenheiro Agrônomo (UESB), Mestrando em Agronomia (UESB), Vitória da Conquista, Bahia.E-mail: thiago.agro@live.com

${ }^{3}$ Engenheiro Agrônomo (UESB), Mestrando em Agronomia (UESB), Vitória da Conquista, Bahia.E-mail: edenilson.eng.agronomo@gmail.com

${ }^{4}$ Graduando em Agronomia, Universidade Estadual do Sudoeste da Bahia. E-mail:willyan.vale@ @otmail.com

${ }^{5}$ Engenheiro Agrônomo, Doutor, Professor Titular (UESB), Vitória da Conquista, Bahia. E-mail: moraisom@ig.com.br
} 


\section{INTRODUÇÃO}

A produção de algodão (Gossypium hirsutum L.) e derivados compõem um importantíssimo setor econômico mundial. A projeção para a safra 2015/16 coloca o Brasil como quinto produtor, competindo com China, Índia, Estados Unidos e Paquistão; na mesma projeção, o Brasil se situa na sexta posição como consumidor e quarto exportador mundial (ICAC, 2015).

A previsão de safra 2014/15 brasileira mantém a Bahia na segunda colocação na produção de pluma com uma produção de 434,1 mil toneladas e o Mato Grosso ainda será o primeiro produtor com 864,6 mil toneladas (CONAB, 2015). Nas últimas décadas a região Oeste da Bahia passou por um ciclo de crescimento econômico intenso e vigoroso, marcado pelo desenvolvimento tecnológico da agricultura (LIMA et al., 2010), sendo responsável atualmente por mais de $90 \%$ da produção de algodão da Bahia.

Um dos fatores limitantes para o sucesso da cultura do algodoeiro tem sido a dificuldade de obter sementes com qualidade física, fisiológica e sanitária capazes de proporcionar o estabelecimento dessa cultura com população ideal e com plântulas uniformes e vigorosas, com respostas diretas no aumento da produção por área plantada (LAUXEN et al., 2010).

Dada à diversidade de cultivares disponíveis em diferentes programas de melhoramento, transgênicas ou não, busca-se trabalhos que auxiliem o produtor na escolha das cultivares a serem plantadas. Portanto, o conhecimento dos testes de qualidade de sementes é de suma importância para a utilização da cultivar mais adequada a necessidade do produtor (MORELLO et al., 2015).

A qualidade das sementes é um parâmetro importante que deve ser visto no processo produtivo de qualquer cultura, pois sucesso de uma lavoura em geral, também está atrelado ao uso de sementes de boa qualidade.

A avaliação da qualidade fisiológica das sementes auxilia no conhecimento do potencial germinativo de um lote em condições favoráveis. Com o resultado desta avaliação podese inferir na determinação da taxa de semeadura, sendo um dado para a comparação do valor de lotes e para a comercialização, pois possibilita a obtenção diferentes resultados comparativos entre laboratórios (CARVALHO e NAKAGAWA, 2012). A avaliação da qualidade fisiológica das sementes deve ser realizada através de testes de germinação e vigor.

Os testes de qualidade de sementes, principalmente o de germinação têm despertado grande interesse pelos produtores, pois consegue identificar possíveis diferenças na qualidade fisiológica entre variados lotes, cujas sementes apresentam poder germinativo semelhante. Porém, este teste apresenta limitações por fornecer resultados que superestimam o potencial fisiológico das sementes, por ser conduzido sob condições consideradas ótimas (BARROS, 2002).

Portanto, é necessário obter maiores informações que permitam identificar as cultivares de algodão que apresentam condições de bom desenvolvimento sob condições de campo e diante do exposto, o presente trabalho objetivou avaliar o potencial fisiológico de cultivares comerciais de algodão cultivadas em Luiz Eduardo Magalhães.

\section{MATERIAL E MÉTODOS}

A pesquisa foi desenvolvida no laboratório de tecnologia de sementes da Universidade Estadual do Sudoeste da Bahia, Campus de Vitória da Conquista, situada a $14^{\circ} 53^{\prime}$ de Latitude Sul e $40^{\circ} 48^{\prime}$ de Longitude Oeste, com altitude média de $876,91 \mathrm{~m}$. Foram utilizadas sementes de algodão, cultivares DP 604, FM 993, BRS 368, TMG 642 e DELTA OPAL ambas cultivadas em Luiz Eduardo Magalhães, durante a safra de 2014/2015.

A avaliação da qualidade fisiológica das sementes foram feitas por meio dos seguintes testes e determinações:

Determinação do teor de água (base úmida): foi determinado em estufa a $105 \pm 3^{\circ} \mathrm{C}$ por $24 \mathrm{~h}$ (BRASIL, 2009), utilizando-se quatro amostras de 50 sementes, para cada cultivar. Os resultados foram expressos em porcentagem.

Peso de mil sementes: determinado conforme a fórmula proposta por BRASIL (2009) utilizando-se oito repetições de 100 sementes, efetuadas através da pesagem em balança com precisão de $0,001 \mathrm{~g}$.

Teste de germinação: foram utilizadas quatro repetições de 25 sementes por cultivar, semeadas em rolos de papel toalha tipo Germitest, umedecidos com água, o equivalente a 2,5 vezes o peso do substrato seco e colocadas para germinar a $25^{\circ}$ C. Nas avaliações foram consideradas como sementes germinadas aquelas que emitiram a raiz primária e a parte aérea que se encontravam aparentemente sadias (BRASIL, 2009) com os resultados expressos em porcentagem.

Primeira contagem de germinação: conduzido, conjuntamente, com o teste de germinação, computando-se a porcentagem de plântulas normais, no quarto dia após a semeadura.

Emergência de plântulas: para essa avaliação, quatro repetições de 25 sementes por cultivar foram semeadas em canteiros de $10 \times 1,0 \mathrm{~m}$, com $10 \mathrm{~cm}$ entre repetições, contendo substrato terra/areia na proporção 1:1. As irrigações foram feitas sempre que necessário, visando o fornecimento de água para a germinação das sementes e emergência das plântulas. A porcentagem de emergência foi obtida considerando as plântulas emergidas, aquelas com os folíolos primários expandidos, até a estabilização do teste, com os resultados expressos em porcentagem.

Índice de velocidade de emergência: para a determinação deste índice foram realizadas contagens diárias a partir da emergência da primeira plântula. A contagem prosseguiu até à estabilização da emergência das plântulas. O índice foi calculado conforme MAGUIRE (1962).

Comprimento de plântulas: ao final do teste de emergência, dez plântulas normais tomadas ao acaso de cada repetição foram utilizadas para se avaliar o comprimento (do colo até o ápice), com auxílio de uma régua graduada em centímetros, sendo os resultados expressos em centímetro por plântula.

Massa seca de plântulas: ao final do teste de emergência, as plântulas emersas provenientes de cada tratamento foram colocadas em sacos de papel do tipo kraft e acondicionadas em estufa com circulação de ar forçado, regulada a $65^{\circ} \mathrm{C}$, aonde permaneceram até atingir peso constante. Em seguida, foram pesadas em balança analítica com precisão de 0,0001 g, sendo os resultados expressos em gramas por plântula.

Condutividade elétrica: quatro subamostras de 50 sementes de cada tratamento foram pesadas em balança com precisão de $0,001 \mathrm{~g}$, colocadas em copos plásticos contendo $75 \mathrm{~mL}$ de 
água deionizada e mantidas no germinador à temperatura de $25{ }^{\circ} \mathrm{C}$ por 24 horas. Após esse procedimento, a condutividade elétrica da solução foi medida por meio de leituras em condutivímetro Digimed (modelo DM 31) e os resultados expressos em $\mu \mathrm{S} . \mathrm{cm}^{-1} \cdot \mathrm{g}^{-1}$ de sementes (VIEIRA e KRZYZANOWSKI, 1999).

Para a analises estatística utilizou-se o delineamento inteiramente casualizado, com quatro repetições. Os dados obtidos foram submetidos à análise de variância e as médias comparadas pelo teste de Tukey a $5 \%$ de probabilidade através do programa estatístico ASSISTAT 7.7.

\section{RESULTADOS E DISCUSSÃO}

Na Tabela 1 consta o resumo da análise de variância para as características teor de umidade (TU) peso de mil sementes (PMS), primeira contagem (PC) germinação (G) índice de velocidade de emergência (IVE), emergência (E), comprimento de plântulas (CP) massa seca de plântulas (MSP) e condutividade elétrica (CE) onde pode ser observado efeito significativo para todas as características estudadas.

Consta-se na tabela 2 , os dados referentes ao teor de água, peso de mil sementes e germinação de diferentes cultivares de algodão. Observa-se que a cultivar DELTA OPAL $(11,74 \%)$ difere-se estatisticamente das cultivares.

Tabela 1. Quadrados médios dos dados referentes à teor de umidade (U), peso de mil sementes (PMS), primeira contagem (PC) germinação (G), índice de velocidade de emergência (IVE), comprimento de plântula (CP), condutividade elétrica (CE) e massa seca de plântulas (MSP) de sementes de algodão (Gossypium hirsutum L.), cultivadas em Luiz Eduardo Magalhães, 2015.

\begin{tabular}{ccccccccccc}
\hline F.V & GL & U & PMS & PC & G & IVE & E & CP & CE & MSP \\
\hline CUL & 4 & $8,57^{* *}$ & $6.7891,97^{* *}$ & $5,25^{* *}$ & $3,214^{* *}$ & $1,534^{* *}$ & $312,8^{* *}$ & $1,135^{* *}$ & $193,219^{* *}$ & $0,246^{* *}$ \\
RES. & 15 & 0,3319 & 0,00117 & 3,3333 & 1,866 & 0,124 & 42,466 & 0,057 & 11,970 & 0,010 \\
\hline CV $\%)$ & 5,37 & 0,04 & 1,86 & 1,38 & 8,95 & 7,73 & 5,38 & 3,25 & 10,20 \\
\hline
\end{tabular}

FV - Fontes de variação; GL - Grau de liberdade; CUL. - Cultivares; RES. - Resíduo. Valores significativos a 1\% (**) e a 5\% (*); ${ }^{\text {ns }}$ - Não significativo

BRS 368, FM 993 e TMG 642 (9,76 11,43 e 10,14\%), porém não difere estatisticamente da cultivar DP 604 (10,53\%). Verifica-se que o teor de água das sementes de algodão apresentou-se uniforme, com variação de 1,98, inferior à amplitude máxima recomendada que é de 2 pontos percentuais, isso mostra que os lotes apresentam uniformidade entre si (MARCOS FILHO, 2005). Do mesmo modo, Dutra e Medeiros (2008) encontraram resultados semelhantes, indicando que o grau de umidade relativamente semelhante entre lotes de sementes de algodão, é importante, pois a uniformidade do teor de água das sementes é essencial para a padronização das avaliações e obtenção de resultados consistentes. O teor de água inicial das sementes é um dos parâmetros primordiais para a regularização dos testes de vigor a serem efetuados, enfatizado que o teor elevado de água pode favorecer o desempenho das sementes nos testes (COIMBRA, 2007).

Já em relação ao peso de mil sementes, consta-se que a cultivar BRS 368 apresentou maior valor $(94,04 \mathrm{~g})$ diferindo estatisticamente das demais cultivares estudadas, porém o menor peso foi verificado para a cultivar DELTA OPAL $(83,75 \mathrm{~g})$. Segundo Bezerra et al. (2004) para muitas espécies o peso da semente é um indicativo de sua qualidade fisiológica, sendo que em um mesmo lote, as sementes pequenas, normalmente, apresentam menor germinação e vigor do que as de tamanho médio e grande. Esses autores ressaltam que, em determinadas situações, estas podem não ser as mais vigorosas. Os menores pesos verificados nos lotes das sementes das cultivares DP 604 e DELTA OPAL (84,41 e $83,75 \mathrm{~g})$ apresentaram maiores valores de germinação em relação as demais cultivares estudas (Tabela 2).

Para os dados de germinação, todas as cultivares analisadas apresentaram germinação superior a $80 \%$, valor mínimo exigido pela legislação vigente para produção e comercialização de sementes de algodão (BRASIL,2009), evidenciando elevado potencial germinativo destas sementes.

Nota-se que a cultivar TMG 642 (97\%) apresentou germinação inferior as cultivares DP 604, FM 993 e Delta Opal (100, 99 e $100 \%)$. Para Frigeri (2007) os lotes de sementes que apresentam porcentual de germinação semelhantes podem exibir comportamentos distintos no campo e/ou no armazenamento.

De acordo com Braz (2009) quando as diferenças no potencial fisiológico entre os lotes de sementes são muito pequenas, provavelmente, estes não são possíveis de serem detectadas pelo teste de germinação.

Tabela 2. Teor de água e peso de mil sementes de sementes de algodão (Gossypium hirsutum L.), cultivadas em Luiz Eduardo Magalhães, 2015.

\begin{tabular}{lccc}
\hline CULTIVARES & Teor de água $(\%)$ & Peso de mil sementes $(\mathrm{g})$ & Germinação $(\%)$ \\
\hline DP 604 & $10,53 \mathrm{ab}$ & $84,41 \mathrm{~d}$ & $100 \mathrm{a}$ \\
FM 993 & $11,43 \mathrm{~b}$ & $87,09 \mathrm{c}$ & $99 \mathrm{a}$ \\
BRS 368 & $9,76 \mathrm{~b}$ & $94,04 \mathrm{a}$ & $99 \mathrm{ab}$ \\
TMG 642 & $10,14 \mathrm{~b}$ & $91,39 \mathrm{~b}$ & $97 \mathrm{~b}$ \\
DELTA OPAL & $11,74 \mathrm{a}$ & $83,75 \mathrm{e}$ & $100 \mathrm{a}$ \\
\hline CV $(\%)$ & 5,37 & 0,04 & 1,38 \\
\hline
\end{tabular}

Médias seguidas pela mesma letra na coluna não diferem significativamente entre si pelo teste de Tukey, a 5\% de probabilidade 
Tabela 3. Primeira contagem de germinação (\%), emergência (\%) e índice de velocidade de emergência (\%) de sementes de algodão (Gossypium hirsutum L.), cultivadas em Luiz Eduardo Magalhães, 2015.

\begin{tabular}{lccc}
\hline CULTIVARES & Primeira contagem (\%) & Emergência (\%) & IVE \\
\hline DP 604 & $99 \mathrm{a}$ & $89 \mathrm{a}$ & $4,34 \mathrm{a}$ \\
FM 993 & $99 \mathrm{a}$ & $82 \mathrm{a}$ & $3,59 \mathrm{bc}$ \\
BRS 368 & $99 \mathrm{a}$ & $93 \mathrm{a}$ & $4,44 \mathrm{a}$ \\
TMG 642 & $94 \mathrm{~b}$ & $70 \mathrm{~b}$ & $3,01 \mathrm{c}$ \\
DELTA OPAL & $100 \mathrm{a}$ & $88 \mathrm{a}$ & $4,31 \mathrm{a}$ \\
\hline CV $(\%)$ & 1,86 & 7,73 & 8,95 \\
\hline
\end{tabular}

Médias seguidas pela mesma letra na coluna não diferem significativamente entre si pelo teste de Tukey, a 5\% de probabilidade.

Cocco (2008) analisando o desempenho fisiológico de sementes de algodão cultivar FM 993, encontrou resultados semelhantes ao deste trabalho, onde os lotes de sementes analisados apresentaram um percentual de germinação de 84 a $98 \%$, mostrando assim um percentual de germinação superior ao exigido pela legislação. Sendo assim, as cultivares foram consideradas adequados para serem comparados quanto ao vigor, uma vez que apresentaram grau de umidade e porcentagens de germinação semelhantes.

Os resultados de primeira contagem de germinação, emergência e índice de velocidade de emergência de sementes de algodão cultivadas em Luiz Eduardo Magalhães estão apresentados na tabela 3. Os valores obtidos na primeira contagem do teste de germinação foram, para a maioria das cultivares, iguais ou semelhantes à germinação, indicando que a totalidade, ou a grande parte das sementes germinadas, já tinham formado plântulas normais quatro dias após a semeadura. Com base nesse teste, a cultivar TMG 642 foi o de menor vigor.

Observa-se que o menor percentual de emergência foi encontrado na cultivar TMG 642 (70\%), mostrando assim ser a de menor vigor, diferindo estatisticamente das demais. Segundo Shuch et al. (2000) sementes com baixo vigor determinaram redução, retardamento e desuniformidade na emergência no campo na cultura de aveia preta, e sementes de vigor elevado produziram plântulas com maior tamanho inicial, o que proporcionou maiores taxas de crescimento no período inicial de crescimento da cultura.

Jauer et al. (2002) observaram diferença entre as cultivares de feijão através dos testes de emergência de plântulas e condutividade elétrica, sendo a cultivar IAPAR 44 a que apresentou menor vigor, dentre aquelas testadas, ou seja, a Xamego, a TPS Bionobre e a TPS Nobre.

A avaliação da qualidade fisiológica da semente para fins de semeadura em campo e de comercialização de lotes é fundamentalmente baseada no teste de germinação, conduzido sob condições favoráveis de umidade, temperatura e substrato, o que permite expressar o potencial máximo de produção de plântulas normais.

Em relação ao índice de velocidade de emergência as cultivares DP 604, BRS 368 e DELTA OPAL (4,34, 4,44 e $4,31 \%)$ possuem maior vigor, indicando que apresentam maior capacidade de originar plântulas mais competitivas nas fases iniciais da cultura, diferindo estatisticamente das cultivares FM 993 e TMG 642 (3,59 e 3,01\%), que apresentam menor vigor.

Segundo Marcos Filho (2005) a utilização de sementes de boa qualidade fisiológica é fator primordial no estabelecimento de qualquer lavoura. Sementes de baixa qualidade, isto é, de potencial de germinação e vigor reduzidos, originam lavouras com baixa população de plantas e em consequência com população inadequada, acarretando sérios prejuízos econômicos.

De acordo com Moraes (2006) atraso ou diminuição na velocidade do processo de germinação aumenta a suscetibilidade das sementes a ataques de microrganismos presentes no solo, reduzindo assim, a emergência de plântulas e, como consequência, comprometendo o estande final da lavoura. Sendo assim, uma germinação rápida e uniforme é de suma importância, uma vez que nas regiões do semiárido os recursos hídricos são bastantes escassos.

Para Thomazini (2011) o vigor das sementes é um conjunto de características que determinam o potencial para emergência rápida e uniforme de plântulas normais, sob ampla diversidade de condições de ambiente.

Os resultados de comprimento de plântulas massa seca de plântulas e condutividade elétrica de sementes de algodão, cultivadas em Luiz Eduardo Magalhães está apresentado na Tabela 4.

Para o comprimento de plântulas, nota-se os maiores valores para a cultivares BRS $368(5,15 \mathrm{~cm})$, não diferindo da cultivar FM $993(4,73 \mathrm{~cm})$, enquanto os menores resultados foram observados nas cultivares DP 604, DELTA OPAL E TMG $642(4,38,4,31$ e $3,72 \mathrm{~cm})$.

Guedes et al. (2009) e Vanzolini et al. (2007) ressaltam que o comprimento de plântulas, ou de parte delas, dado em função do número de sementes colocadas em teste, é mais sensível para classificar lotes com diferenças de qualidade fisiológica, em comparação com a forma tradicional de considerar o comprimento com base no número de plântulas normais obtidas no final do teste.

Tavares et al. (2008) trabalhado com sementes de soja e Almeida et al. (2009) com sementes de cenoura que o desenvolvimento das raízes incrementa a absorção de nutrientes minerais, aumentando a área foliar e a expressão do vigor das plantas.

Para a característica, massa seca de plântulas, os maiores resultados foram observados nas cultivares BRS 368, DELTA OPAL e DP 604 (1,2625, 1,1710 e 1,0730g), já os menores valores foram para as cultivares FM 993 e TMG $642(0,7765$ e $0,6947 \mathrm{~g}$ ).

Schuch e Finatto (2006) trabalhando com plantas de soja, provenientes de sementes de alta qualidade fisiológica, apresentaram altura superior às plantas originadas de sementes com qualidade inferior. 
Tabela 4. Comprimento de plântulas, massa seca de plântulas e condutividade elétrica de sementes de algodão (Gossypium hirsutum L.), cultivadas em Luiz Eduardo Magalhães, 2015.

\begin{tabular}{lccc}
\hline CULTIVARES & $\begin{array}{c}\text { Comprimento } \\
\text { de Plântulas } \\
(\mathrm{cm})\end{array}$ & $\begin{array}{c}\text { Massa } \\
\text { seca de } \\
\text { Plântulas } \\
(\mathrm{g})\end{array}$ & $\begin{array}{c}\text { Condutividade } \\
\text { elétrica } \\
\left(\mu \mathrm{S} . \mathrm{cm}^{-1} \cdot \mathrm{g}^{-1}\right)\end{array}$ \\
\hline DP 604 & $4,38 \mathrm{~b}$ & $1,0730 \mathrm{a}$ & $85,38 \mathrm{~d}$ \\
FM 993 & $4,73 \mathrm{ab}$ & $0,7765 \mathrm{~b}$ & $99,71 \mathrm{c}$ \\
BRS 368 & $5,15 \mathrm{a}$ & $1,2625 \mathrm{a}$ & $92,55 \mathrm{~d}$ \\
TMG 642 & $3,72 \mathrm{c}$ & $0,6947 \mathrm{~b}$ & $109,51 \mathrm{~b}$ \\
DELTA OPAL & $4,31 \mathrm{~b}$ & $1,1710 \mathrm{a}$ & $146,35 \mathrm{a}$ \\
\hline CV $(\%)$ & 5,38 & 10,20 & 3,25 \\
\hline
\end{tabular}

Médias seguidas pela mesma letra na coluna não diferem significativamente entre si pelo teste de Tukey, a 5\% de probabilidade.

As cultivares Delta Opal e TMG 642 apresentaram maior liberação de eletrólitos durante a embebição das sementes, consequentemente em maiores valores de condutividade elétrica $\left(146,35\right.$ e $\left.109,51 \mu \mathrm{S} . \mathrm{cm}^{-1} . \mathrm{g}^{1}\right)$ respectivamente. Os menores resultados de condutividade elétrica foram observados para as cultivares DP 604 e BRS 368 (85,38 e $\left.92,55 \mu \mathrm{S} \mathrm{cm}^{-1} \mathrm{~g}^{-1}\right)$, mostrando assim, um maior vigor destas sementes em relação as demais cultivares.

Cocco (2012) avaliando o desempenho físiológico de sementes de algodão, observou que os lotes de sementes com maiores valores lixiviação de solutos (2, 5 e 6) (324,81, 320,01 e $\left.322,53 \mu \mathrm{S} . \mathrm{cm}^{-1} \cdot \mathrm{g}-{ }^{1}\right)$, corresponderam a menores porcentagens de plântulas normais, indicando assim, baixo potencial fisiológico, quando comparados com os lotes 1,3 e 4 $\left(306,50,291,26\right.$ e $\left.298,24 \mu \mathrm{S} . \mathrm{cm}^{-1} . \mathrm{g}^{1}\right)$. Sendo assim, quanto menor a liberação de eletrólitos na solução de embebição maior será a integridade das membranas celulares, consequentemente maior vigor as sementes terão.

Segundo Kruse et al. (2006) as sementes mais deterioradas apresentam menor integridade das membranas e, como consequência, ocorre o extravasamento do conteúdo celular para o meio, constatado pelo aumento da quantidade de lixiviados durante o processo de embebição. Para Marcos Filho (2005) o teste de condutividade elétrica tem se mostrado eficiente para a avaliação do vigor de sementes de várias espécies.

Diante disto, o teste de condutividade elétrica apresenta grande vantagem em comparação ao índice de velocidade de emergência (IVE) pela facilidade de execução e rapidez na obtenção dos resultados. Assim, a avaliação de vigor pelo teste de condutividade elétrica mostra-se promissor para sementes de algodão, indicando a necessidade da continuidade desses estudos.

Pode se observar que a qualidade fisiológica das cultivares de sementes de algodão produzidas no município de Luiz Eduardo Magalhães, apresentam germinação alta e semelhante entre eles, porém quando avaliado o vigor destas, os lotes apresentam variações no vigor, indicando desuniformidade entre lotes, provenientes de locais diferentes de produção.

\section{CONCLUSÕES}

A cultivar TMG 642 demonstrou baixa qualidade fisiológica das sementes, quando comparados com as cultivares DP 604, FM 993, BRS 368, e DELTA OPAL.
Os testes de germinação, condutividade elétrica e índice de velocidade de germinação mostraram eficiência na separação de cultivares de sementes de algodão em níveis de vigor.

O teste de condutividade elétrica pode ser utilizado para identificar diferença de vigor nos lotes de sementes, após período de 24 horas.

As sementes de algodão apresentam percentual de germinação acima dos padrões mínimos exigidos para comercialização.

\section{REFERÊNCIAS BIBLIOGRÁFICAS}

ALMEIDA, A. S.; TILLMANN, M. A. A.; VILLELA, F. A.; PINHO, M. S. Bioativador no desempenho fisiológico de sementes de cenoura. Revista Brasileira de Sementes, Brasília, v. 31, n. 3, p. 87-95, 2009.

BARROS, D.I.; NUNES, H.V.; DIAS, D.C. F.; BHERING, M.C. Comparação entre testes de vigor para avaliação da qualidade fisiológica de sementes de tomate. Revista Brasileira de Sementes, Brasília, v. 24, n. 2, p.12-16, 2002.

BEZERRA, A. M. E.; MOMENTÉ, V. G.; MEDEIROS FILHO, S. Germinação de sementes e desenvolvimento de plântulas de moringa (Moringa oleifera Lam.) em função do peso da semente e do tipo de substrato. Horticultura Brasileira, Brasília, v.22, n.2, p.295-299,2004.

BRASIL. Ministério da Agricultura, Pecuária e Abastecimento. Regras para Análise de Sementes. Brasília: MAPA/ACS, 2009. 399p.

BRAZ, M.R.S.; ROSSETO, C.A.V.; Correlação entre testes para a avaliação da qualidade de sementes de girassol e emergência das plântulas em campo. Ciência Rural, Santa Maria, v.39, n.7, p.1997- 2003, 2009.

CARVALHO, N. M.; NAKAGAWA, J. Sementes: ciência, tecnologia e produção. 4. ed. Jaboticabal: Funep, p.588, 2012.

COCCO, D. L. Desempenho fisiológico de sementes de algodão. 2012.26f. Dissertação (Mestrado em Agronomia). Faculdade de Agronomia Eliseu Maciel. Universidade Federal de Pelotas. Pelotas,2012.

COIMBRA, R. de A.; TOMAZ, C. de A.; MARTINS, C. C.; NAKAGAWA, J. Teste de germinação com acondicionamento dos rolos de papel em sacos plásticos. Rev. Brasileira de Sementes, Londrina, v. 29. $\mathrm{n}^{\mathrm{o}} 1, \mathrm{p} .92-97,2007$.

CONAB - COMPANHIA NACIONAL DE ABASTECIMENTO. Cronograma de divulgação de safras. Disponível em http://conab.gov.br/conteudos.php? $\mathrm{a}=1252 \& \mathrm{t}=\quad$ Acesso em: 1 nov. de 2015.

DIAS, D.C.F.S.; MARCOS FILHO, J. Testes de condutividade elétrica para avaliação do vigor de sementes de soja (Glycine $\max$ (L.) Merrill). Scientia Agricola, Piracicaba, v.53, n.1, p.31-42,1996. 
DUTRA, A. S.; MEDEIROS FILHO, S. Teste de deterioração controlada na determinação do vigor em sementes de algodão. Revista Brasileira de Sementes, v. 30, n. 1, p.1923, 2008 .

FRIGERI, T. Interferência de patógenos nos resultados dos testes de vigor em sementes de feijoeiro. 2007. 77f. Dissertação (Mestrado em Agronomia). Faculdade de Ciências Agrárias e Veterinárias. Universidade Estadual Paulista, Jaboticabal, 2007.

GUEDES, R. S.; ALVES, E. U.; GONÇALVES, E. P; VIANA. J. S.; MEDEIROS. M. S.; LIMA. C. R. Teste de comprimento de plântula na avaliação da qualidade fisiológica de sementes de Erythrina velutina Willd. Semina: Ciências Agrárias, Londrina, v. 30, n. 4, p. 793802, 2009.

ICAC INTERNATIONAL COTTON ADVISORY COMMITTEE. Cotton this month. Disponível em https://www.icac.org/cotton_info/publications/updates/20 15/English/ectm5_15.pdf Acesso em: 3 nov. de 2015.

JAUER, A.; MENEZES, N. L.; GARCIA, D. C. Tamanho de sementes na qualidade fisiológica de cultivares de feijoeiro comum. Revista da Faculdade de Zootecnia, Veterinária e Agronomia, Uruguaiana, v.9, n.1, p.121$127,2002$.

KRUSE, N. D. et al. Estresse oxidativo em girassol (Helianthus annuus) indica sinergismo para a mistura dos herbicidas metribuzin e clomazone. Planta Daninha, v. 24, n. 2, p. 379-390, 2006

LAUXEN, L. R.; VILlELA, F. A.; SOARES, R. C. Desempenho tratadas com tiametoxan. Revista Brasileira de Sementes, Brasília, vol. 32, n. 3 p. 061-068, 2010.

LIMA, L. A. S. MARTINS, E. S. GOMES, M. P. REATTO, A. PASSO, D. P. CASTRO, K. B. CARVALHO JÚNIOR, O. A. GOMES, R. A. T. Caracterização geomorfológica do município de Correntina, Oeste Baiano, escala 1:100.000. Boletim de Pesquisa e Desenvolvimento (Embrapa Cerrados), v. 287, p. 5-33, 2010.MAGUIRE, J. D. Speed of germination-aid selection and evaluation for seedling emergence and vigor. Crop Science, Madison, v.2, p.176-177, 1962.

MARCOS FILHO, J. Fisiologia de sementes de plantas cultivadas. Piracicaba: Fealq, 2005. 495p.

MACHADO, R. C. R. Efeito da desidratação osmótica no acúmulo de prolina livre em discos foliares e na germinação de sementes de vinte cultivares de feijão (Phaseolus vulgaris L.). 1976. 42f. Dissertação (Mestrado em Fitotecnia). Viçosa: Universidade Federal de Viçosa.

MENDONÇA, E. A. F.; AZEVEDO, S. C.; GUIMARÃES, S. C.; FIGUEIREDO E ALBUQUERQUE, M. C. Testes de vigor em sementes de algodoeiro herbáceo. Revista Brasileira de Sementes, Pelotas, v.33, n.3, p.001-009, 2008.
MORAES, S. A. Amendoim: Principais doenças, manejo integrado e recomendações de controle. [online], 2006. Disponívelem:http://www.infobibos.com/Artigos/2006_2/ Amendoim/index.htm>. Acesso em: 1 jul. de 2015.

MORELLO, C. L.; PEDROSA, M. B.; SUASSUNA, N. D.; FARIAS, F. J. C.; SILVA FILHO, J. L.; PERINA, F. J.; FREIRE, E. C.; ALENCAR, A. R.; TAVARES, J. A.; OLIVEIRA, W. P. Desempenho de Cultivares de Algodoeiro no Cerrado do Estado da Bahia, Safra 2013/2014. EMBRAPA algodão. Campina Grande. 2015

SANTOS, F.et al. Teste de envelhecimento acelerado para avaliação da qualidade de sementes de alface e almeirão. Revista Brasileira de Sementes, Pelotas, v.33, n.2, p.322323, 2011.

SCHUCH, L. O. B.; FINATTO, J. A. Comportamento de plantas isoladas de soja em função da qualidade fisiológica das sementes In: CONGRESSO DE INICIAÇÃO CIENTÍFICA, 14. E ENCONTRO DE PÓSGRADUAÇÃO, 7, 2006, Pelotas. Anais. Pelotas: Editora e Gráfica Universitária UFPel, 2006. 1 CD-ROOM.

SCHUCH, L. O. B.; NEDEL, J. L.; ASSIS, F. N.; MAIA, M. S. Emergência a campo e crescimento inicial de aveia preta em resposta ao vigor de sementes. Revista Brasileira de Agrociência, Pelotas, v. 6, n. 2, p. 97-101, 2000.

VANZOLINI, S.; NAKAGAWA, J. Testes de vigor baseados no desempenho de plântulas. Informativo ABRATES, Brasília, v. 17, n. 1-3, p. 76-83, 2007.

VIEIRA, R. D.; KRZYZANOWSKI, F. C. Teste de condutividade elétrica. In: KRZYZANOWSKI, F. C.; VIEIRA, R. D.; FRANÇA NETO, J. B. (Ed.). Vigor de sementes: conceitos e testes. Londrina: ABRATES, 1999. Cap. 4, p. 1-26.

THOMAZINI, A.; MARTINS, L.D. Qualidade física e fisiológica de sementes de girassol (Helianthus annuus L.) cultivar MG2 em condições de casa de vegetação e laboratório. Enciclopédia Biosfera, Centro Científico Conhecer - Goiânia, vol.7, n.12; 2011.

TAVARES, S.; CASTRO, P. R. C.; RIBEIRO, R. V.; ARAMAKI, P. H. Avaliação dos efeitos fisiológicos de tiametoxam no tratamento de sementes de soja. In: GAZZONI, D. L. (Ed.). Tiametoxam: uma revolução na agricultura brasileira. Petrópolis: Vozes, 2008. p. 193204. 